\title{
Flow Routing in the Natural Channel of the Ichu River Experimental Basin through Artificial Neural Networks
}

Iván Ayala Bizarro, Joel Oré Iwanaga, David Requena Machuca, Richard Oré Cayetano, Edwin Torres Condori and Edwin Montes Raymundo

Department of Civil Engineering, National University of Huancavelica, Huancavelica 09001, Peru

\begin{abstract}
The objective of the investigation is to carry out the flow routing in the natural channel of the experimental basin of the Ichu river, by means of the Artificial Intelligence technique of ANNs (Artificial Neural Networks). Generally, hydrological and hydraulic methods require different parameters of the river channel, while the ANNs method simplifies the amount of data. The study area is located in the experimental basin of the Ichu river, upstream of the city of Huancavelica in an area of $607 \mathrm{~km}^{2}$. A calibrated and validated model of the rain-runoff process was developed, with data recorded in 6 automatic meteorological stations (rainfall) and one hydrological station (runoff). The model HEC-1 was used to model the rain-runoff process and the Muskingun-Cunge method for the flood rounting, generating historical records for 5 stretches of the Ichu riverbed and obtaining 39 maximum historical records in the 2016 periods and 2017. The model obtained values of Nash-Sutcliffe efficiency coefficients $(E)$ equal to 0.851 and 0.828 for the calibration and validation stage, respectively. The ANNs were built with different architectures to train and obtain the architecture that best fits the historical phenomena. Finally, the architecture 1-5-1 presented a better fit, whose statistical $E$ was values of 0.881 and 0.859 in the training and validation stage respectively.
\end{abstract}

Key words: Rain-runoff process, flood routing, ANNs.

\section{Introduction}

The Ichu river experimental basin is located in the Huancavelica region of Peru. Currently, the basin is instrumented and monitored by the National University of Huancavelica, Department of Civil Engineering and financed by the Socioeconomic Development Fund of Camisea (FOCAM). The instrumentation is made up of 6 meteorological stations and one hydrological station, they are monitoring the climatological variables in the basin to prevent flooding in the urban area of the city of Huancavelica.

In order to analyze the flood prevention, the flood rounting procedure in the natural channel of the Ichu river has been carried out, using the artificial intelligence technique ANNs (Artificial Neural Networks). Currently, the application of ANNs is

Corresponding author: Iván Ayala Bizarro, master, main research field: hydrological and hydraulic modeling to prevent flooding. carried out very frequently in different fields of engineering.

Flow routing is commonly analyzed using numerical techniques such as the Muskingum-Cunge method, however, this method requires geometric, geomorphological and hydrological information of the channel. Many basins do not have this information or in any case these can be of a high cost.

On the other hand, the technique of artificial intelligence, specifically the ANNs, simplifies the amount of input parameters to obtain output hydrograph results, being called the design or flood hydrograph. The ANNs correspond to a cause-effect process, that is, input hydrographs (cause) and output hydrographs (effect). Through a trial-and-error process, the efficient and robust architecture is determined to determine the output hydrographs in the study basin.

The present investigation makes use of the meteorological and hydrological data of the experimental river basin of the Ichu river to carry out 
the transit of the flow with the purpose of analyzing the floods in the city of Huancavelica, applying the method of the ANNs.

\section{Materials and Methods}

The flow routing is a mathematical procedure to predict the change in magnitude, velocity and shape of an flood wave as a function of time (flow hydrograph) at one or more points along a water course [1].

\subsection{Instrumentation of the Basin}

The Ichu river basin is hydrographically located on the eastern slope of the Mantaro river basin. It has an area of $607.00 \mathrm{~km}^{2}$, considering the hydrological station as the lowest point, corresponds to a large and elongated basin according to its classification and has a more frequent altitude of $4,559.38$ m.s.n.m.

Fig. 1 shows the distribution of the instrumentation of the meteorological and hydrological equipment of the Ichu river basin. There are 06 meteorological stations, denominated: Huancevelica, Sacsamarca, Chuñuranra, Lachocc, Cachimayo and Pucapampa. The hydrological station is called Huancavelica. The recorded information corresponds to a time interval of 10,15 and 30 minutes in the rainfall, represented by hietograms and the flows represented by hydrographs.

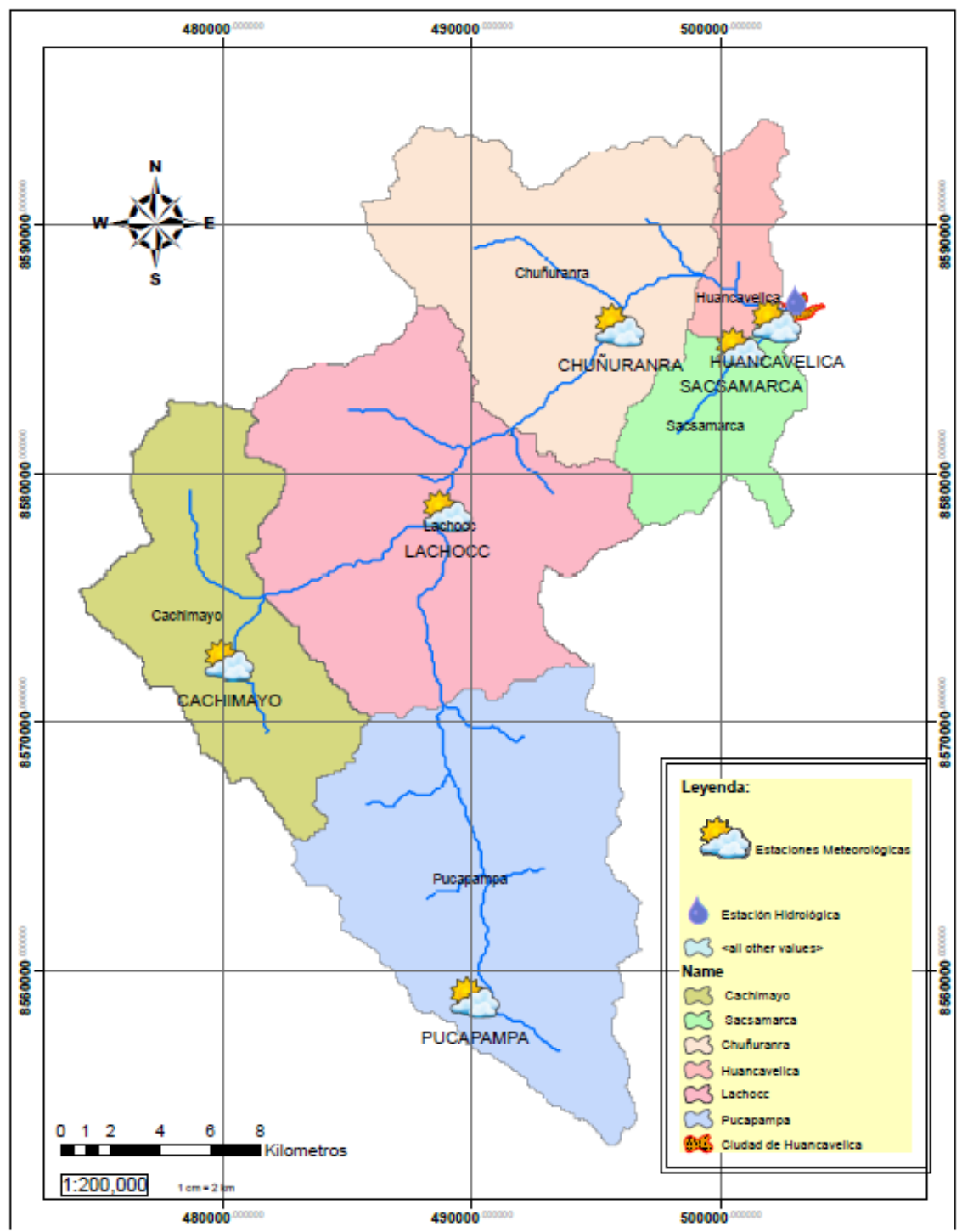

Fig. 1 Location of meteorological stations and hydrological station in the Ichu river experimental basin funded by FOCAM of the National University of Huancavelica. 


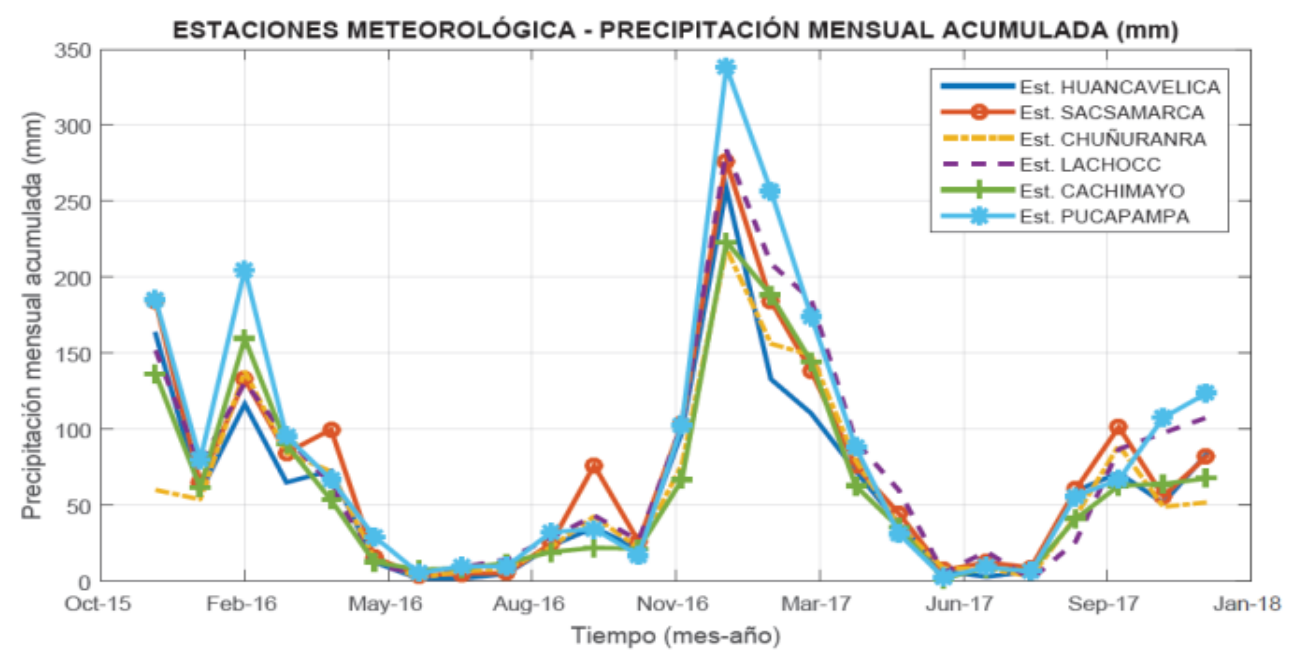

Fig. 2 Accumulated monthly precipitation of meteorological stations in the monitoring period corresponding to 2015 -2017.

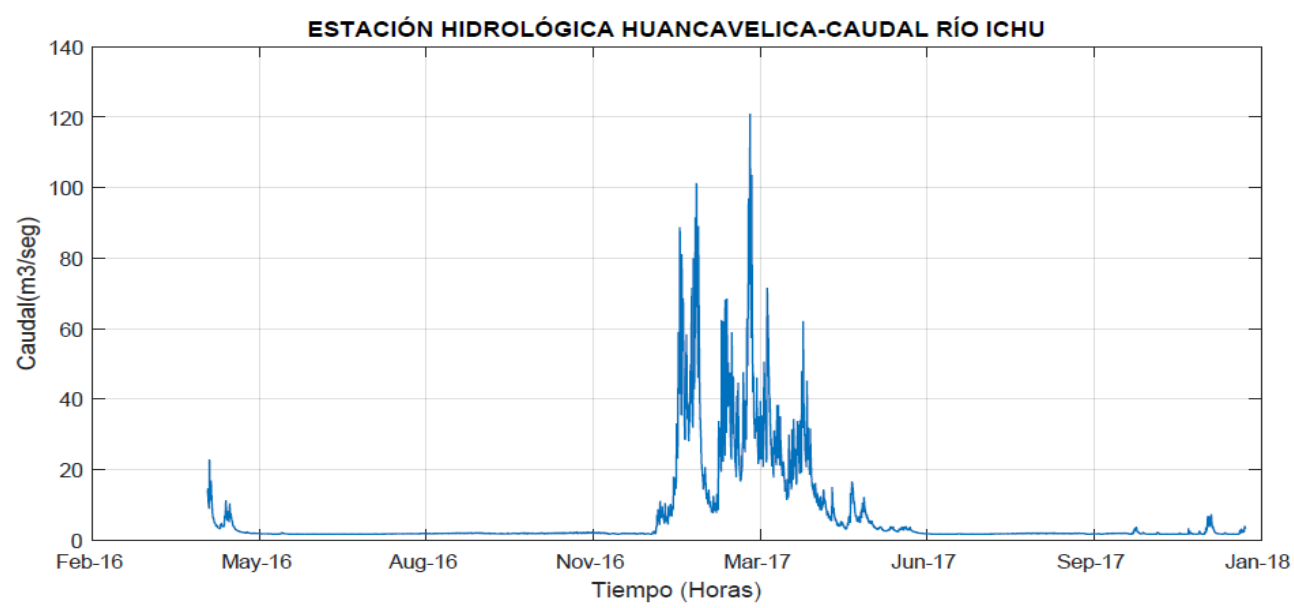

Fig. 3 Daily flows recorded at the hydrological station by automatic equipment and validated by an ADCP (Acoustic Doppler Current Profiler) of the FOCAM UNH project.

For the model, short-duration precipitation (storms) was used, with the objective of evaluating instantaneous flows produced in the sub-basins.

Fig. 2 shows the accumulated monthly rainfall recorded from 2015 to 2017, which corresponds to the meteorological stations of Huancavelica, Sacsamarca, Chuñuranra, Lachocc, Cachimayo and Pucapampa.

Fig. 3 shows the flows recorded in the Huancavelica hydrological station, whose values are used in the output neurons of the proposed model.

\subsection{Rain-Runoff Model}

To obtain the historical hydrographs of each section, the HEC-1 model has been applied, determining the maximum floods registered in the periods 2016 and
2017. Fig. 4 shows the modeling diagram of the rain-runoff process of the basin and channel of the Ichu river.

For the rain-runoff transformation of the basin, the HEC-HMS program of the United States Army Corps of Engineers has been used, considering the Curve Number method of the SCS (Soil Conservation Service), currently NRCS (Natural Resource Conservation, Service). Likewise, the synthetic unit hydrograph proposed by the SCS has been used.

Also, it has been considered the records of the flows of the Huancavelica hydrological station to determine the base flow or initial flow. Finally, for the transit of hydrographs, the Muskingum-Cunge method has been used. 


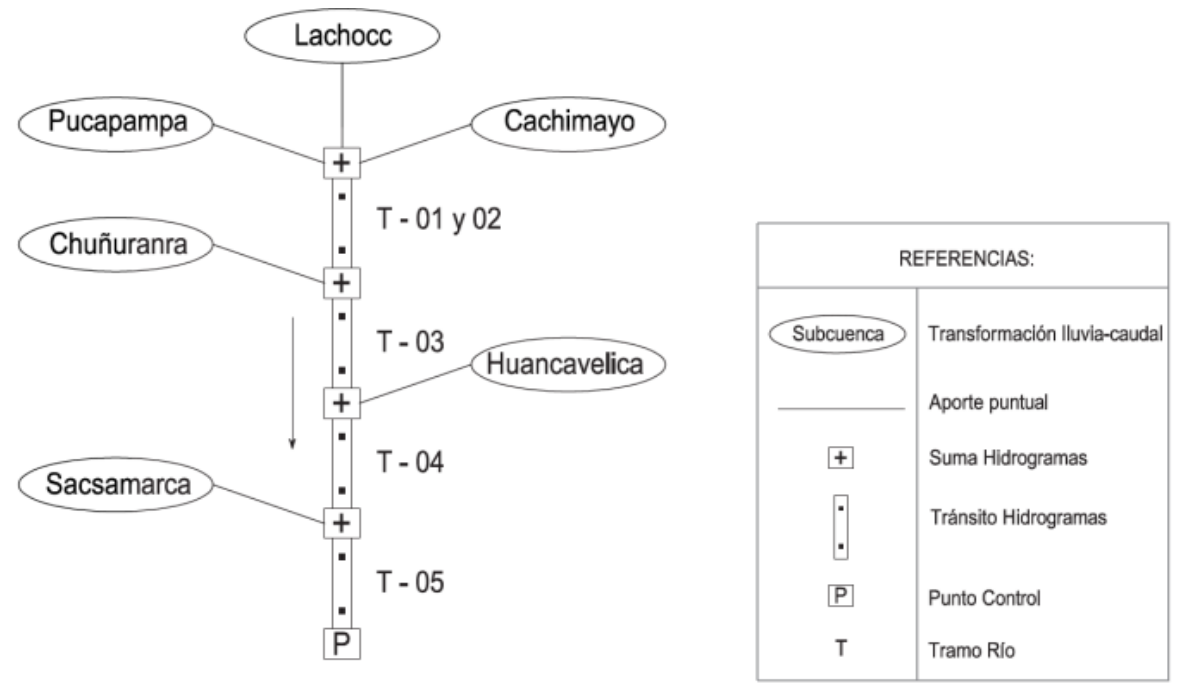

Fig. 4 Simulation scheme to determine the rain-runoff process of the Ichu river experimental basin.

\subsubsection{Muskingum-Cunge}

Cunge (1969), used the precision of the diffusion method, that is, hydraulic method, with the method of simple Muskingum. The method is adapted for cases in which hydrological data are not available, that is, flow data, but if the hydraulic data of the channel are available. In this way, the Muskingum-Cunge method is classified as a hydrological method $[2,3]$.

According to Refs. [3-8], the transit equation of the Muskingum-Cunge method defined in the typical configuration of the four-point grid is:

$$
Q_{j+1}^{n+1}=C_{0} Q_{j}^{n+1}+C_{1} Q_{j}^{n}+C_{2} Q_{j+1}^{n}
$$

where: $Q$ is the download; $j$ is a spatial index; $n$ is a temporary index; $C_{0}, C_{1}$ and $C_{2}$ are rounting coefficients. The routing coefficients are the following:

$$
\begin{aligned}
C_{0} & =\frac{-1+C+D}{1+C+D} \\
C_{1} & =\frac{1+C-D}{1+C+D} \\
C_{2} & =\frac{1-C+D}{1+C+D}
\end{aligned}
$$

where $C$ and $D$ are Courant and Reynolds numbers respectively [7].

The Courant number $(C)$ is the ratio of the speed of the flood wave and the speed of the network.

$$
C=c \frac{\Delta t}{\Delta x}
$$

The Reynolds number $(D)$ is the ratio of the hydraulic diffusivity to the diffusivity of the grid.

$$
D=\frac{q}{s_{0} \cdot c \cdot \Delta x}
$$

The speed of the wave is defined as follows:

$$
c=\beta^{Q} / A=\beta q / d
$$

where: $q$ is Unit width width, $s_{0}$ is slope of the channel, $c$ is Celerity of the wave, $\Delta x$ is space intervals, $\Delta t$ is time intervals, $\beta$ is an exponent of the classification, $A$ is flow area and $d$ is depth of flow.

To test the model, the Nash-Sutcliffe efficiency coefficient $(E)$ was used, in this way, to know the level of significance of the model. The equation is a function of observed flows $\left(Q_{o b s}\right)$, simulated flows $\left(Q_{\text {sim }}\right)$ and average flows $\left(\overline{Q_{o b s}}\right)$ :

$$
E=1-\frac{\sum_{j=1}^{m}\left(Q_{o b s, j}-Q_{s i m, j}\right)^{2}}{\sum_{j=1}^{m}\left(Q_{o b s, j}-\overline{Q_{o b s, j}}\right)^{2}}
$$

\section{$2.3 \mathrm{ANNS}$}

An ANN is a dynamic computing system consisting of a large number of simple elements of processing (neuron) very interconnected, inspired by the structure of the brain, based on learning through experience, which processes information by means of its dynamic state in response to external stimuli [8-10]. This 
method allows the use of very simple computational operations (additions, multiplication and fundamental logic elements) to solve complex problems, especially those that are not analytical and/or non-linear and/or non-stationary and/or stochastic [11].

Fig. 5 identifies three basic elements of the neuronal model:

(1) A set of synapses or feeder links, each of which is characterized by a weight.

- The dendrites (inputs- $X_{i}$ ): They bring information in the form of electrical impulses to the body.

- The synaptic weights $\left(W_{i}\right)$ : The inputs that come from other neurons are assigned a weight, a factor of importance. This weight, which is a number, is modified during the training of the neural network, and it is here where the information that will make the network serve one purpose or another is stored [12]. The weights can be positive (excitation) or negative (inhibition) [13].

- The axon (output $-Y_{i}$ ): It transmits information in the form of electrical impulses from the body to other neurons through the synapse process $[12,14]$.

- Threshold $\left(W_{0}\right)$.

(2) The summation: to add the input signals, weighted by the respective synapses of the neuron; the operations described here constitute a linear combination [15].

(3) Propagation rule or activation function: calculating the activity status of a neuron; transforming the global input (minus the threshold) into a value (state) of activation (post-synaptic). This function limits the range of amplitude of the output signal to some finite value, whose range usually goes from 0 to 1 or from -1 to 1 . This is so, because a neuron can be totally inactive, that is, 0 or -1 or active $1[15,16]$.

The vector $\mathrm{X}=\left(x_{1}, x_{2}, x_{3}, . ., x_{\mathrm{n}}\right)$ is the input and vector of weights $\mathrm{W}=\left(w_{1}, w_{2}, . ., w_{\mathrm{n}}\right)$ equivalent to the synaptic connections in a real neuron, the $w_{0}$ is the threshold of action or activation and the scalar $Y$ corresponds to the output of the unit. The activity

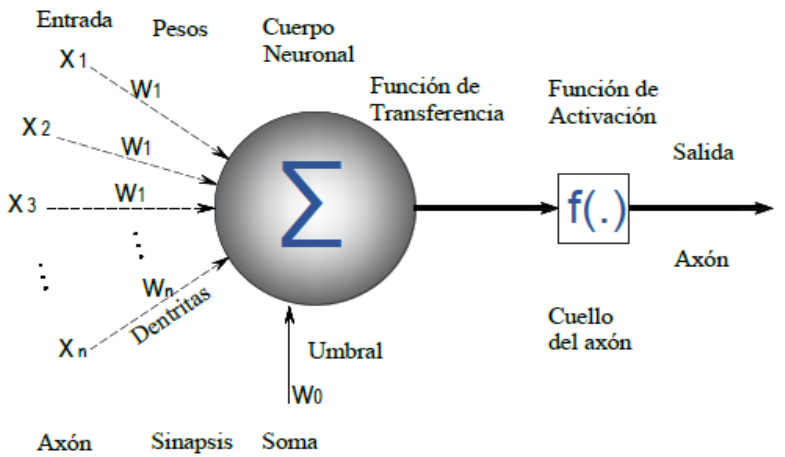

Fig. 5 Typical representation of an artificial neuron.

consists of generating a single output from the application of the activation function $f(x)$ to the weighted sum of the input, from the following equation [10], the input value in the threshold is 1 , while its weight is $W_{0}$, therefore, $W_{0}$ and $\mathrm{XW}$ are added to be the argument of $f$, the transfer function [14].

$$
Y=f\left(\sum_{i=1}^{m} X_{i} W_{i}+w_{0}\right)
$$

Mechanism of learning: The learning capacity of a neural network is achieved by applying a learning algorithm, called training. Learning is not an individual ability of a single neuron. It is a collective process of the entire neural network [17]. Learning means that given a set of observations and a function structure an algorithm is used to find a specific function related to the observations [14].

There are a variety of learning rules that establish when and how the connection weights change [18]. The training algorithms or the procedures for adjusting the values of the ANNs connections can be classified into two groups: Supervised and Unsupervised [12].

Validation: It must be verified if the neural network can solve new problems, of the general type, for which it has been trained. Therefore, for the purpose of validating the neural network, another set of data is required, called the validation or testing set [16].

One of the most important aspects in the construction and development of ANNs is the ability of the network to generalize from examples, avoiding the simple memorization of learning patterns, and 
providing a correct response to individuals not presented during the training phase [9].

\section{Results}

\subsection{Estimation of Sub-basin Parameters}

Fig. 1 shows 06 sub-basins whose hydrological parameters are summarized in Table 1.

\subsection{Ichu River Flow Channel}

The Ichu river starts at an altitude of 4,110 m.s.m., with UTM coordinates 489,162.91 m East and $8,579,986.00 \mathrm{~m}$ South, in the place called Lachocc. The drainage order is 6, with an average Manning coefficient of 0.034 . It has a route of $22.1 \mathrm{~km}$ with an average slope of $1.93 \%$, up to the hydrological station, located at the coordinates of 503,048.80 m East and $8,586,670.95 \mathrm{~m}$ South, of the city of Huancavelica.

For the analysis flow routing in the Ichu riverbed, it has been divided into 5 segments (Fig. 6). Table 2 shows the physiological characteristics of each section.

\subsection{Rain-Runoff Model}

\subsubsection{Rain-Runoff Simulation Using the HEC-1} Model

Fig. 7 shows the first results of the calculated hydrographs, that is, results of the HEC-1 model and the observed hydrographs, corresponding to the hydrological station data. To improve the results, the calibration stage of the model was performed.

\subsubsection{Calibration of the HEC-1 Model}

Fig. 8 shows the results of the calibration stage. This stage has been obtained by performing the test-error procedure, between the flow generated by the HEC-1 model and the flow recorded by the hydrological station. The evaluation of the Nash-Sutcliffe coefficient of the modeled flows and observed flows is equal to 0.851 , qualifying a very good adjustment.

Table 3 shows the results of the delay time and number curve of the individual calibrated storms, showing an increase of $21 \%$ on average of the initial delay time in the sub-basins. The $\mathrm{CN}$ parameter is a very sensitive parameter and has significant influence by several parameters of each basin, included by the previous precipitation, that is, soil moisture. It is recommended that each storm has a unique $\mathrm{CN}$ value.

\subsubsection{Validation of the HEC-1 Model}

To carry out the validation stage, new events are assigned as income, the same ones that were not used in the calibration stage.

Fig. 9 shows the flow event corresponding to the date 9 and 10 April 2016, observing a similarity between both flows. The model reached a value of $E$ equal to 0.828 , corresponding to the validation stage, with good significance.

Table 1 Parameters of the Ichu river sub-basin.

\begin{tabular}{lclll}
\hline Sub-basin & Area $(\mathrm{km})$ & $\mathrm{Tr}(\mathrm{min})$ & $\mathrm{CN}$ & $\mathrm{Ia}(\mathrm{mm})$ \\
\hline Pucapampa & 162.96 & 224.76 & 71.83 & 19.92 \\
Lachocc & 158.857 & 124.24 & 73.32 & 18.49 \\
Cachimayo & 94.33 & 111.33 & 76.40 & 15.69 \\
Chunuranra $^{\sim}$ & 125.267 & 147.86 & 74.77 & 17.14 \\
Sacsamarca & 42.088 & 88.50 & 78.72 & 13.73 \\
Huancavelica & 22.016 & 80.23 & 76.05 & 16.00
\end{tabular}

where: $\mathrm{Tr}$ is the delay time, $\mathrm{CN}$ is curve number, Ia is the initial Abstraction.

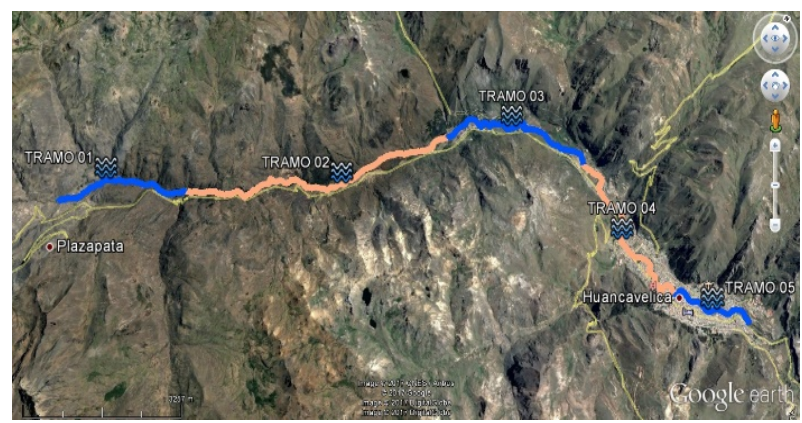

Fig. 6 Spatial view of the analysis sections for the stream flow rounting from Ichu river.

Table 2 Physical characteristics of the stretches of the river.

\begin{tabular}{|c|c|c|c|c|c|}
\hline Stretch & Length & Pending & Sinuosity & Manning & Width \\
\hline river & thalweg & & valley & & \\
\hline Ichu & $(\mathrm{km})$ & $(\%)$ & $(\mathrm{km} / \mathrm{km})$ & (n) & (m) \\
\hline 01 & 3.45 & 3.16 & 1.124 & 0.033 & 18.5 \\
\hline 02 & 7.38 & 3.10 & 1.141 & 0.034 & 24.0 \\
\hline 03 & 4.55 & 1.45 & 1.315 & 0.034 & 28.5 \\
\hline 04 & 4.28 & 0.68 & 1.223 & 0.034 & 30.0 \\
\hline 05 & 2.18 & 0.50 & 1.211 & 0.035 & 24.0 \\
\hline
\end{tabular}



Artificial Neural Networks

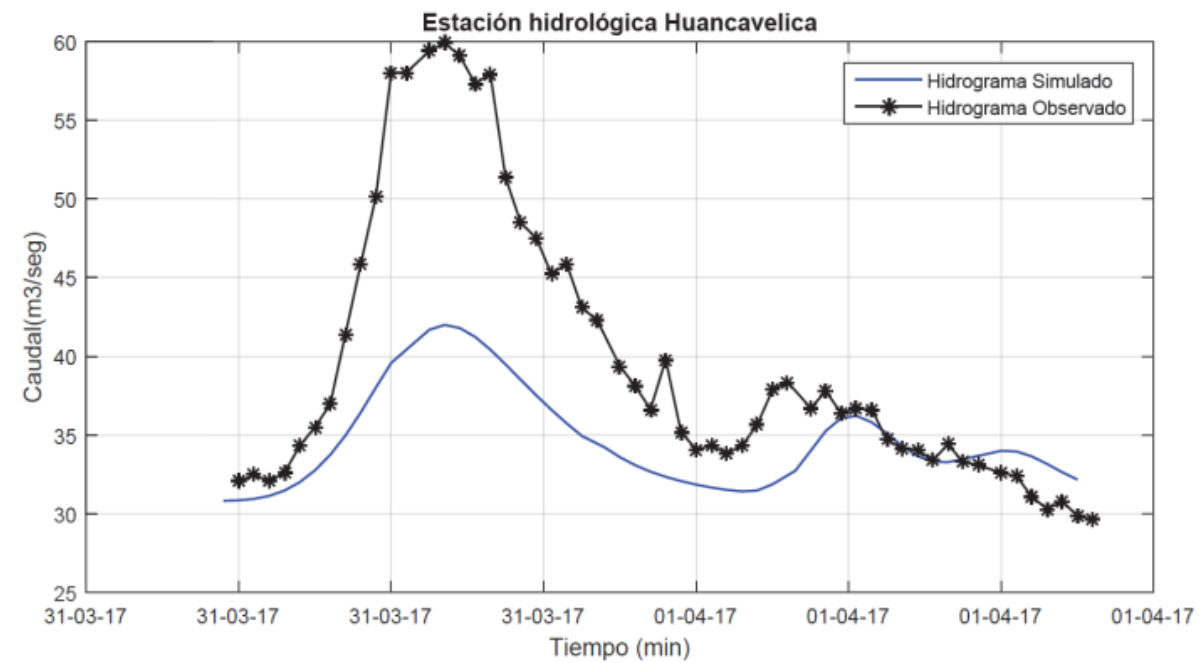

Fig. 7 Results without calibration of the output hydrograph using the HEC-1 model and results of the hydrograph observed through the hydrological station called Huancavelica.

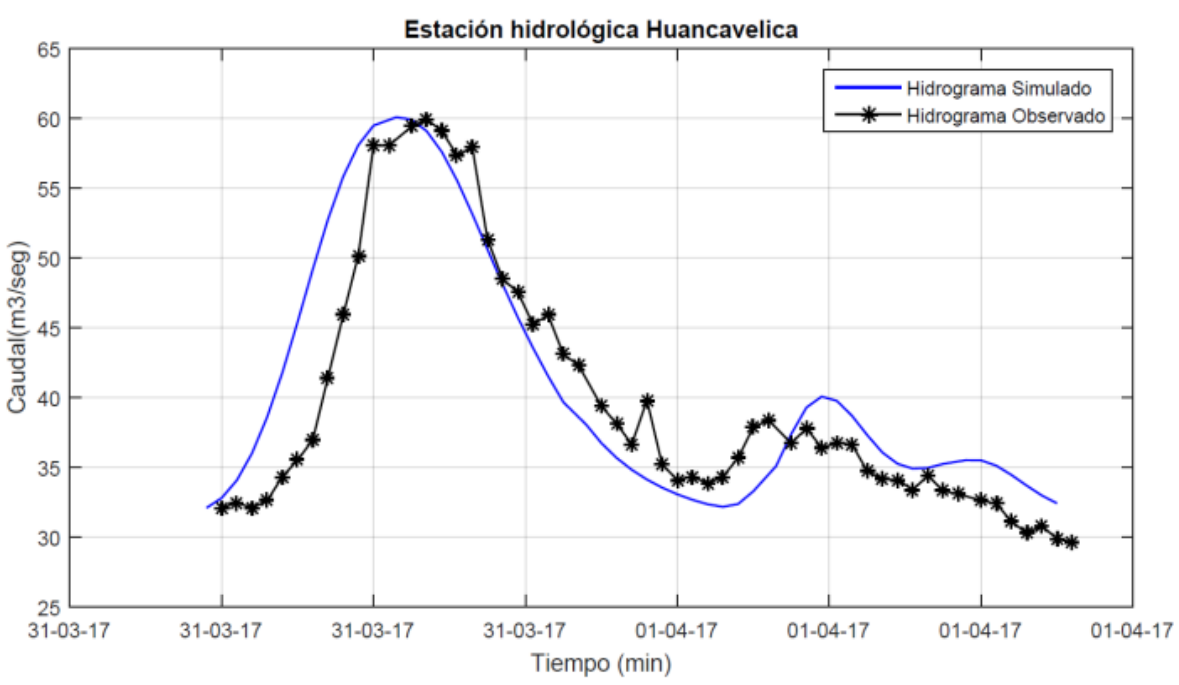

Fig. 8 Results with calibration of the output hydrograph using the HEC-1 model and results of the hydrograph observed through the hydrological station.

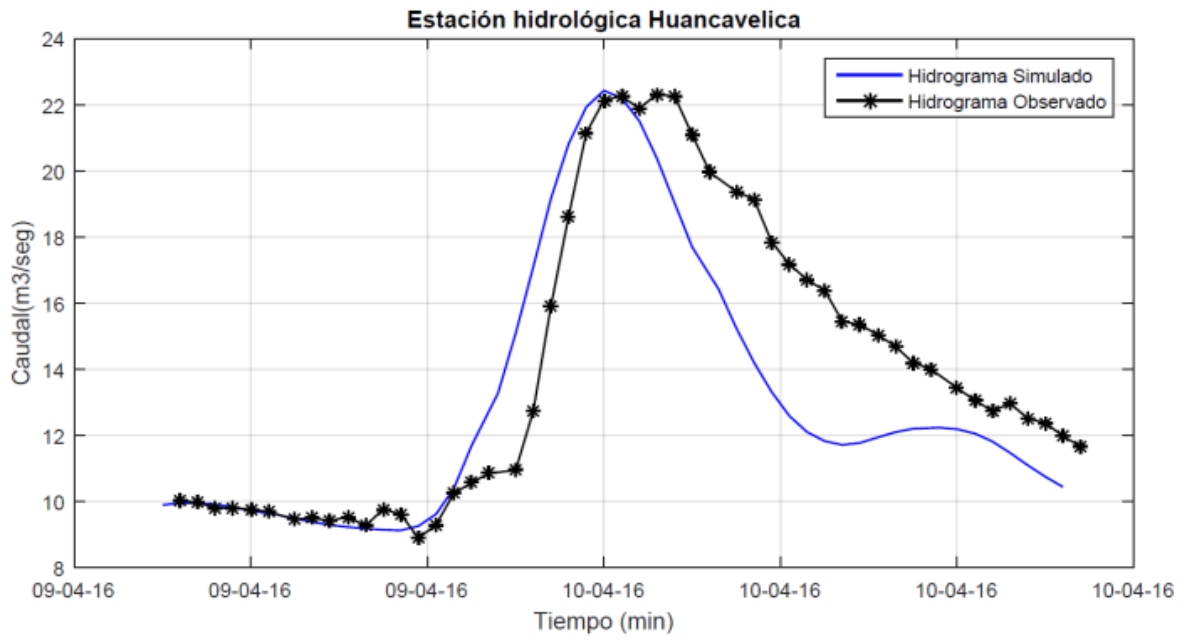

Fig. 9 Results of validation of simulated and observed hydrographs. 
Table 3 Calibrated parameters of each sub-basin of the Ichu river.

\begin{tabular}{llll}
\hline Sub-basin & $\operatorname{Tr}(\mathrm{min})$ & Increase $\operatorname{Tr}(\%)$ & Average CN \\
\hline Pucapampa & 428.4 & 14.42 & 75.83 \\
Lachocc & 261.0 & 26.08 & 76.56 \\
Cachimayo & 225.0 & 21.36 & 77.61 \\
Chuñuranra & 285.6 & 15.81 & 76.97 \\
Sacsamarca & 181.8 & 23.17 & 74.83 \\
Huancavelica & 168.0 & 25.56 & 76.37 \\
\hline
\end{tabular}

\subsection{Generation of Historical Hydrographs}

Once the calibrated and validated rainfall-runoff model for the Ichu river experimental basin was obtained, the generation of historical hydrographs of 39 storms for 5 stretches under study was carried out, as shown in Table 4.

\subsection{Flow Routing through ANNS}

The development of stream flow routing with ANNs is done with the programming language of Matlab, which has a Toolbox called "nntool", which corresponds to the use of ANNs.

\subsubsection{Artficial Neural Network Architecture}

Different architectures of ANNs were constructed with the following parameters.

- Type of network: Feed-forward backprop-MLP

- Learning function: learngdm-Supervised

- Performance function: mse

- Number of layers: 3 (1: entry, 1: hidden and 1: exit)

- Number of neurons: 2+n (1: entry, n: occult and 1: exit)

- Activation function: Logsig, Tansig and Purelin

3.4.2 Training of the Architecture of the ANNs

For the training stage, the hydrograph of February 11-12, 2017 of section 04 was used.

The architecture of the ANNs for the first exploration will be with a defined input layer, a variable sigmoidal hidden layer and a defined linear output layer, as shown in Fig. 10. Therefore, the trial-error procedure will modify the number of neurons in the hidden layer, starting from 4 neurons and ending in 30 neurons.
Table 4 Description of analysis storms.

\begin{tabular}{|c|c|c|}
\hline Number & Start date & End date \\
\hline 01 & 08/04/2016 00:00:00 & 10/04/2016 12:00:00 \\
\hline 02 & 10/04/2016 12:00:00 & 11/04/2016 10:00:00 \\
\hline 03 & 18/04/2016 20:00:00 & 20/04/2016 12:00:00 \\
\hline 04 & 20/04/2016 16:00:00 & $21 / 04 / 2016$ 12:00:00 \\
\hline 05 & 21/04/2016 10:00:00 & 23/04/2016 12:00:00 \\
\hline 06 & 04/01/2017 10:00:00 & 07/01/2017 00:00:00 \\
\hline 07 & 07/01/2017 12:00:00 & 08/01/2017 22:00:00 \\
\hline 08 & 09/01/2017 12:00:00 & 12/01/2017 00:00:00 \\
\hline 09 & 15/01/2017 12:00:00 & 17/01/2017 12:00:00 \\
\hline 10 & 17/01/2017 12:00:00 & 19/01/2017 12:00:00 \\
\hline 11 & 19/01/2017 12:00:00 & 21/01/2017 06:00:00 \\
\hline 12 & 22/01/2017 06:00:00 & 24/01/2017 12:00:00 \\
\hline 13 & 24/01/2017 12:00:00 & 25/01/2017 12:00:00 \\
\hline 14 & 25/01/2017 12:00:00 & 27/01/2017 14:00:00 \\
\hline 15 & 27/01/2017 12:00:00 & 28/01/2017 12:00:00 \\
\hline 16 & 10/02/2017 10:00:00 & 11/02/2017 14:00:00 \\
\hline 17 & 11/02/2017 14:00:00 & 12/02/2017 16:00:00 \\
\hline 18 & 12/02/2017 14:00:00 & 13/02/2017 12:00:00 \\
\hline 19 & 13/02/2017 12:00:00 & 14/02/2017 12:00:00 \\
\hline 20 & 22/02/2017 12:00:00 & 24/02/2017 10:00:00 \\
\hline 21 & 25/02/2017 12:00:00 & 26/02/2017 06:00:00 \\
\hline 22 & 26/02/2017 06:00:00 & 27/02/2017 10:00:00 \\
\hline 23 & 27/02/2017 10:00:00 & 28/02/2017 06:00:00 \\
\hline 24 & 28/02/2017 12:00:00 & 01/03/2017 07:00:00 \\
\hline 25 & 05/03/2017 16:00:00 & 06/03/2017 10:00:00 \\
\hline 26 & 06/03/2017 12:00:00 & 07/03/2017 12:00:00 \\
\hline 27 & 07/03/2017 16:00:00 & 09/03/2017 06:00:00 \\
\hline 28 & 09/03/2017 18:00:00 & 12/03/2017 12:00:00 \\
\hline 29 & 15/03/2017 12:00:00 & 17/03/2017 09:00:00 \\
\hline 30 & 17/03/2017 10:00:00 & 18/03/2017 12:00:00 \\
\hline 31 & 22/03/2017 19:00:00 & $23 / 03 / 2017$ 20:00:00 \\
\hline 32 & 24/03/2017 12:00:00 & 27/03/2017 12:00:00 \\
\hline 33 & 29/03/2017 12:00:00 & $30 / 03 / 2017$ 12:00:00 \\
\hline 34 & 30/03/2017 12:00:00 & 31/03/2017 09:00:00 \\
\hline 35 & 31/03/2017 09:00:00 & 01/04/2017 12:00:00 \\
\hline 36 & 02/04/2017 12:00:00 & 04/04/2017 12:00:00 \\
\hline 37 & 10/04/2017 16:00:00 & 11/04/2017 16:00:00 \\
\hline 38 & 11/04/2017 16:00:00 & 14/04/2017 12:00:00 \\
\hline 39 & 17/04/2017 18:00:00 & 19/04/2017 06:00:00 \\
\hline
\end{tabular}

Figs. 11-13 show the results of the first stage of training of the proposed models. It can be seen that in this case, the adjustment is not adequate according to the output hydrograph. 


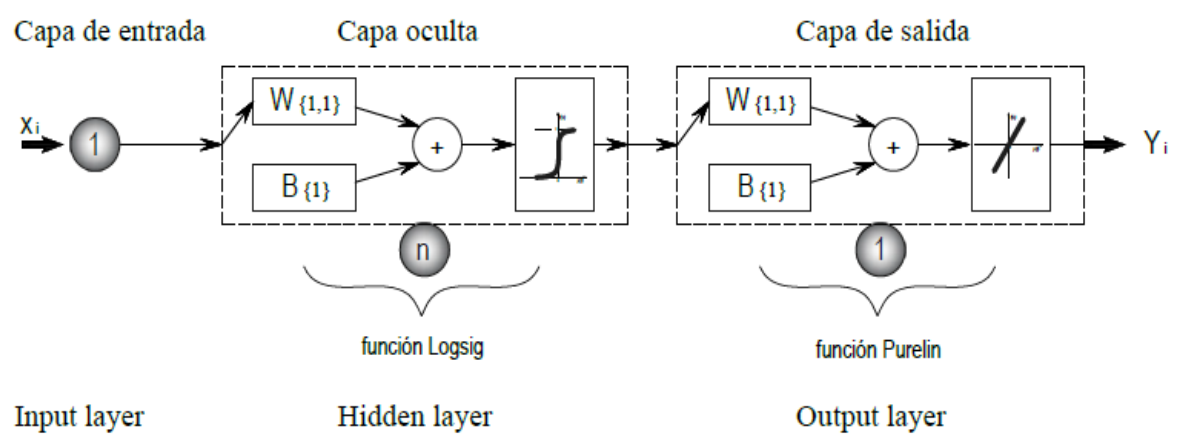

Fig. 10 Characteristics of ANNs with architecture 1-n-1.

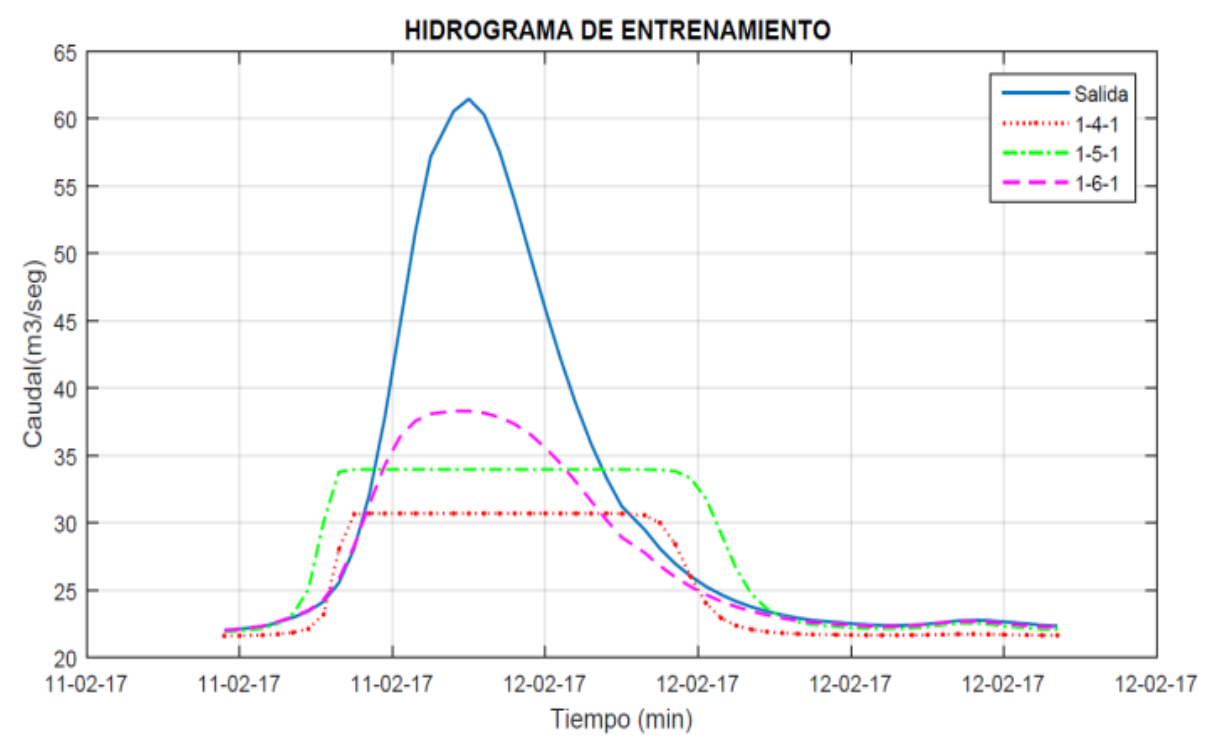

Fig. 11 Result of the hydrographs during the training process with 1-n-1 architectures $(n=4,5$ and 6$)$.

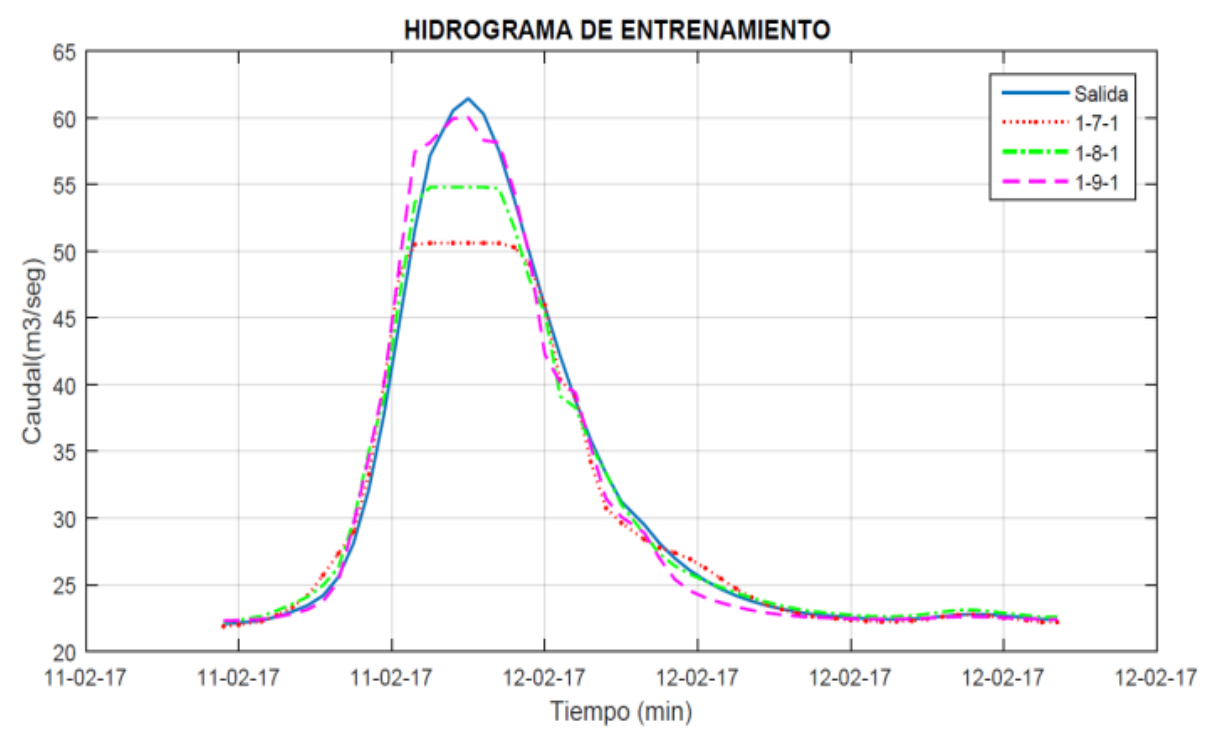

Fig. 12 Result of the hydrographs during the training process with 1-n-1 architectures $(n=7,8$ and 9). 


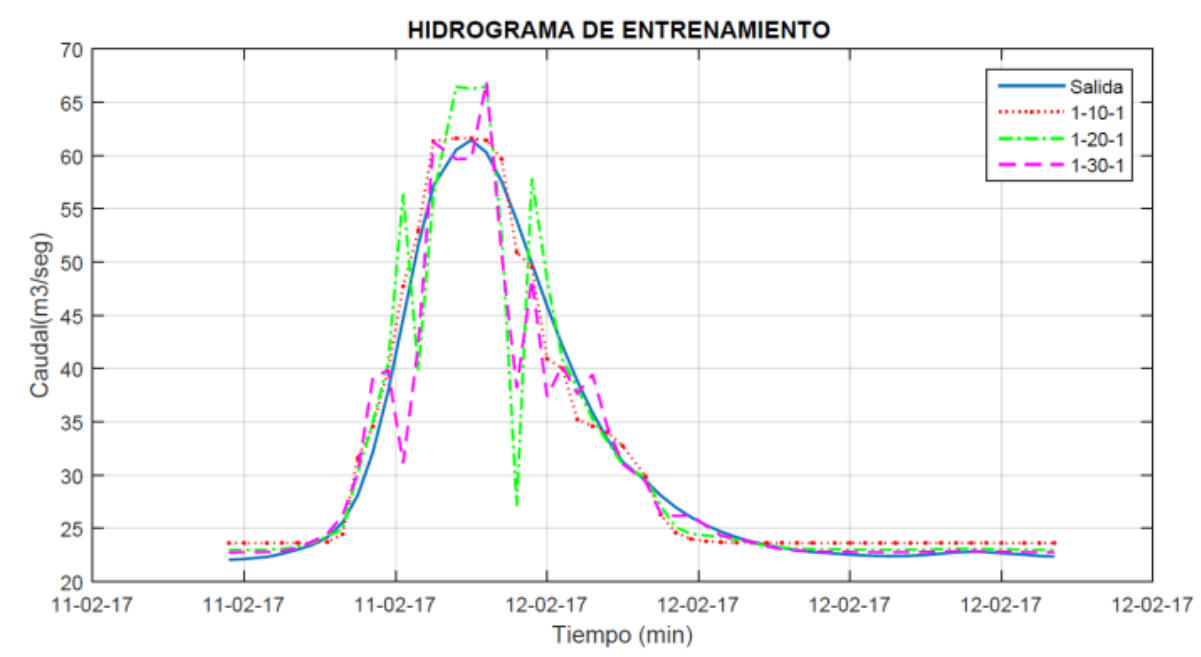

Fig. 13 Result of the hydrographs during the training process with 1-n-1 architectures $(n=10,20$ and 30).

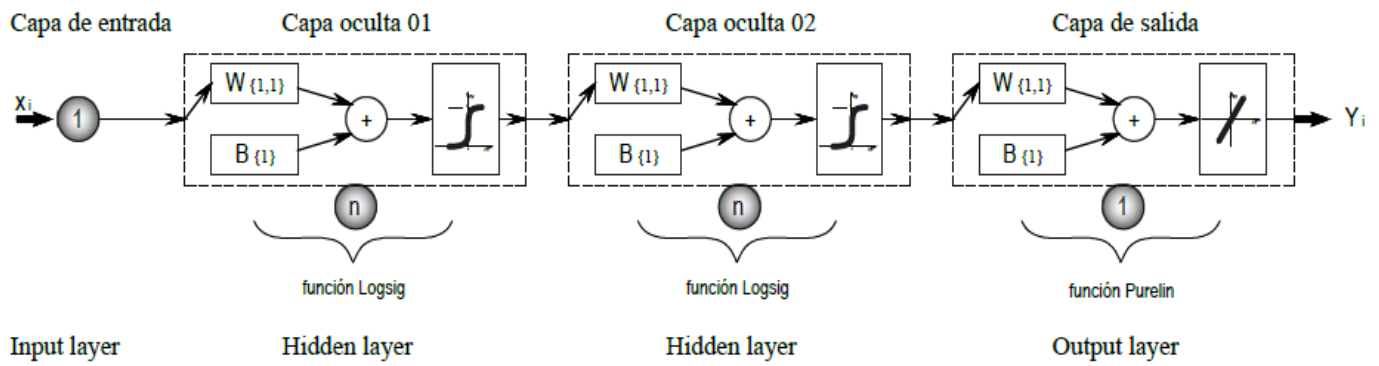

Fig. 14 Characteristics of ANNs with architecture 1-n-n-1.

The architecture of the ANNs for the second scan is: a defined input layer, two hidden layers with a variable Logsig activation function and an output layer with a defined Purelin function, as shown in Fig. 14. In the same way, the hidden layers are those that vary the number of neurons.

Figs. 15-17 show the training of the second exploration of the network with different architectures.

The results of the second exploration defined, are not adjusted properly in the initial and final values of the hydrograph, therefore, the architectures assumed are discarded. As a third exploration, we assume the architecture 1-n-1, hidden layer and output with Purelin function, as shown in Fig. 18.

Figs. 19 and 20 show the results for different neurons in the hidden layer.

Fig. 20 shows the architecture 1-5-1, where the results of the output hydrograph are suitably adjusted to the observed hydrographs. Therefore, the selected architecture is $1-5-1$, that is, an input layer with a neuron, a hidden layer with 5 linear activation function neurons and finely an output layer with a linear transfer neuron, as seen in Fig. 21.

The value of the efficiency coefficient Nash-Sutcliffe $E$ reached a value of 0.881 in the present training stage.

\subsubsection{Validation of the Architecture of the ANN}

From the previous results, the validation and application stage of the ANNs with the architecture $1-5-1$ is carried out, in the different case studies.

Case 01: The first experiment, shown in Fig. 22, shows the hydrograph of entry and exit, the hydrological transit by the method of Muskingum-Cunge and the application of the ANNs of section 4 of the flood from 11-12 February in 2017. It is observed that the ANNs fits perfectly the output hydrograph, it can be seen how the Muskingum-Cunge method has deficiencies in the maximum peak and has values lower than the maximum observed expense. 
Flow Routing in the Natural Channel of the Ichu River Experimental Basin through Artificial Neural Networks

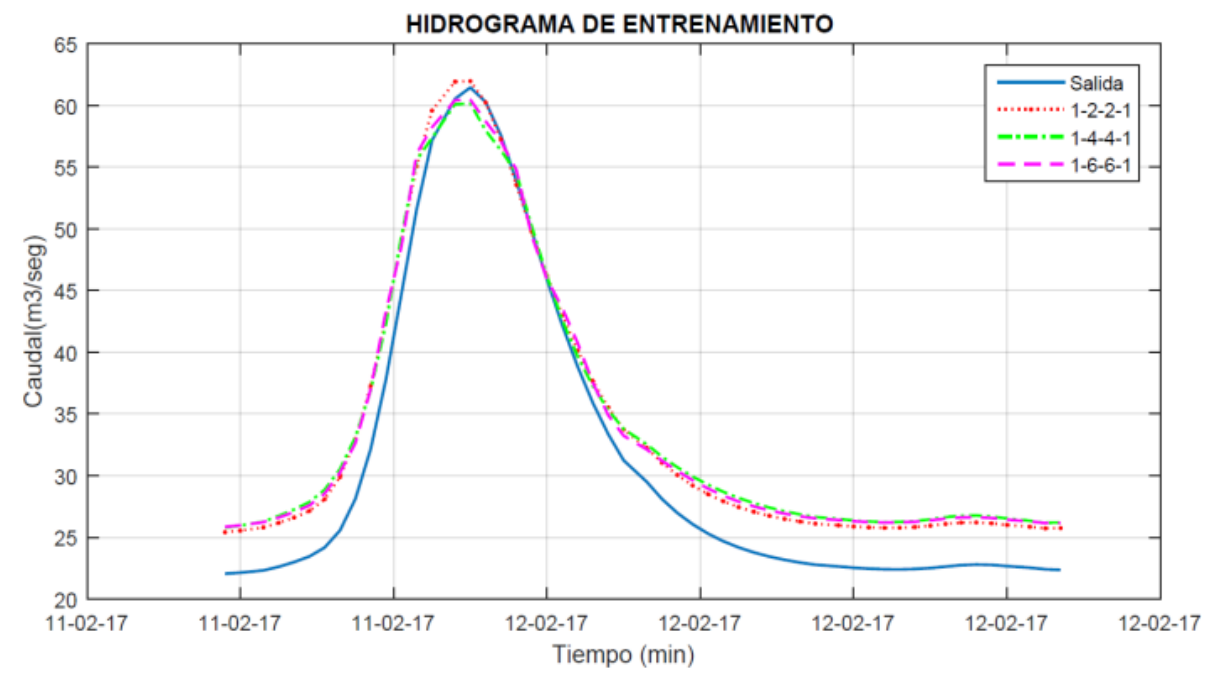

Fig. 15 Result of the hydrographs during the training process with architectures 1-n-n-1 $(n=2,4$ and 6).

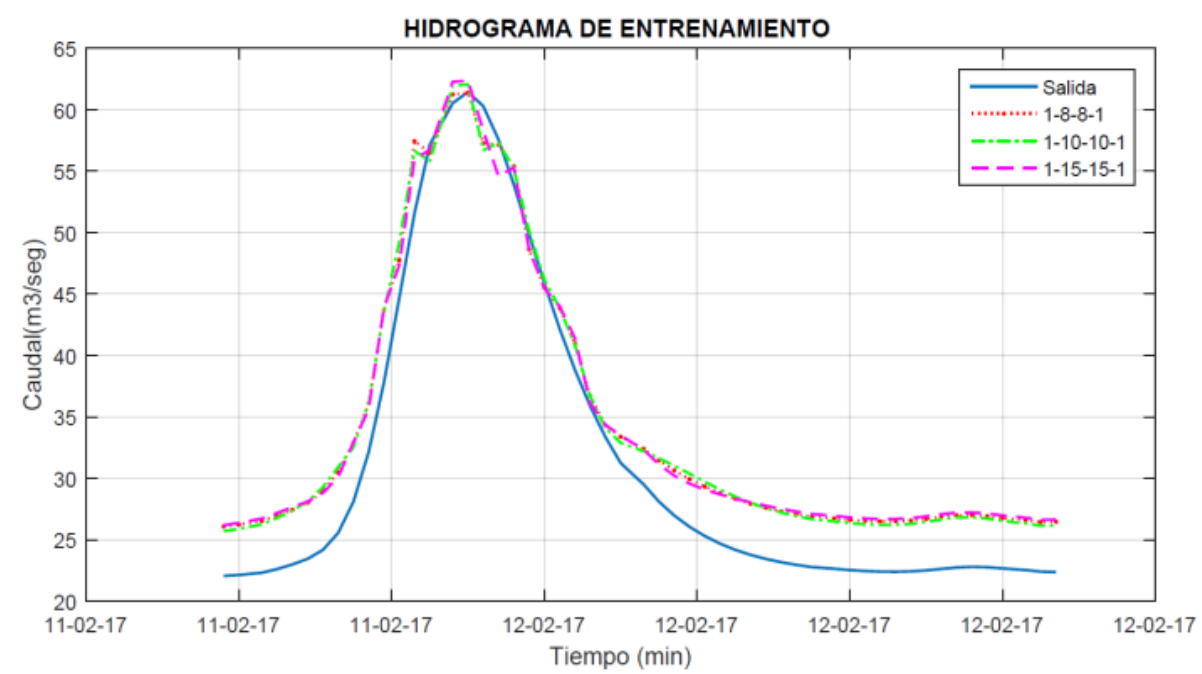

Fig. 16 Result of the hydrographs during the training process with architectures $1-n-n-1(n=8,10$ and 15$)$.

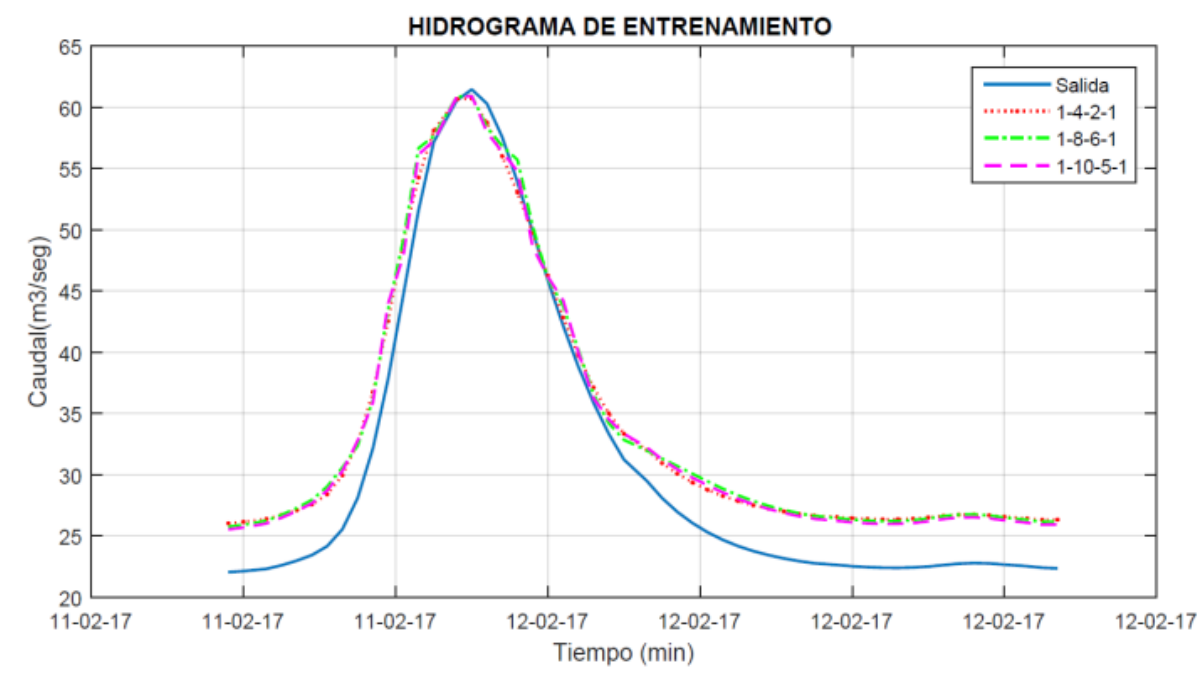

Fig. 17 Result of the hydrographs during the training process with architectures $1-n-n-1(n=2,4,5,6$ and 10$)$. 

Artificial Neural Networks

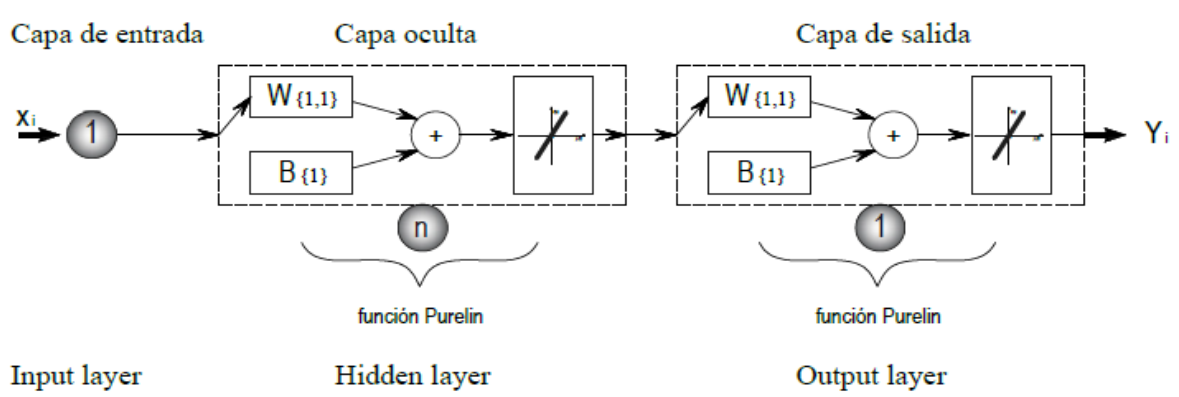

Fig. 18 Characteristics of ANNs with architecture 1-n-1.

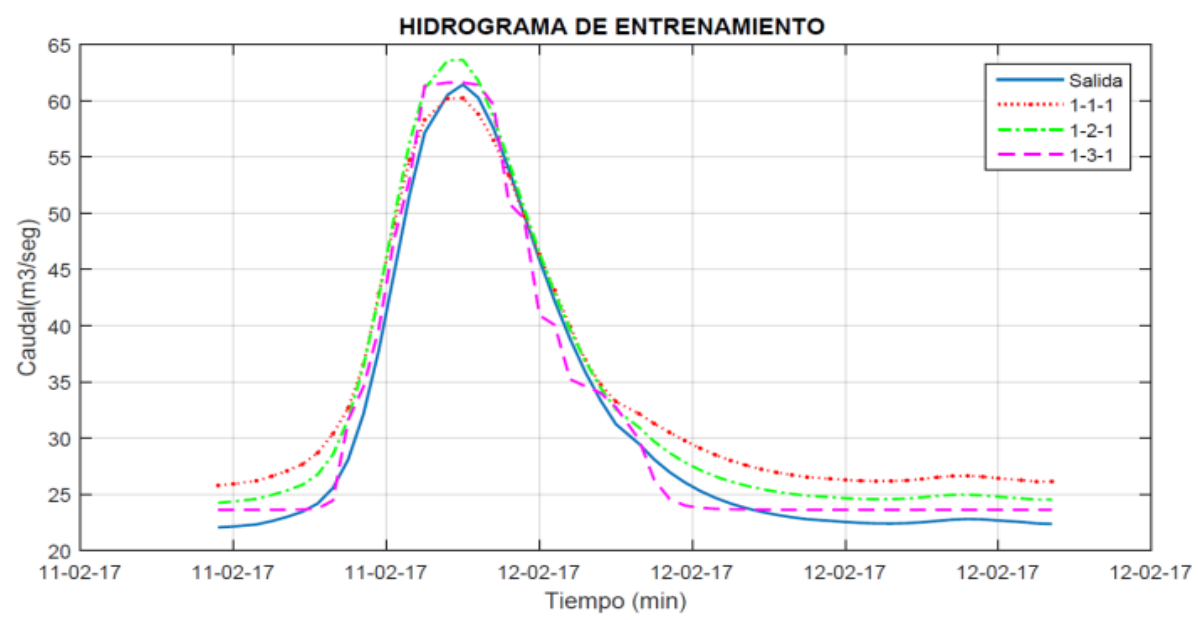

Fig. 19 Result of the hydrographs during the training process with 1-n-1 architectures $(n=1,2$ and 3).

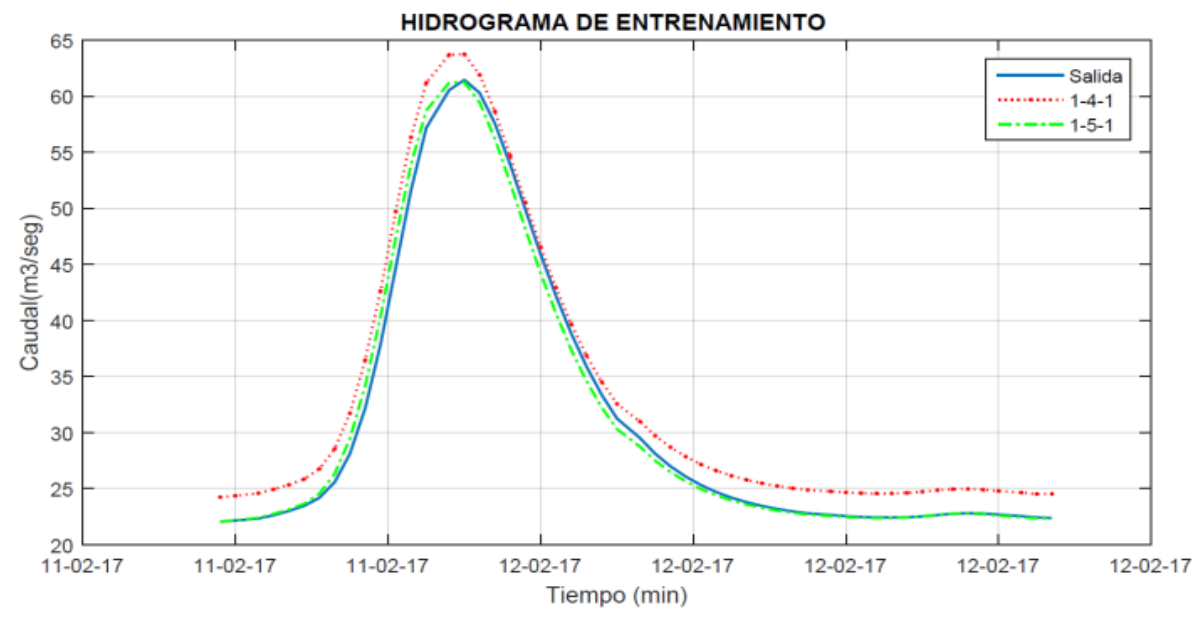

Fig. 20 Result of the hydrographs during the training process with 1-n-1 architectures $(n=4$ and 5).

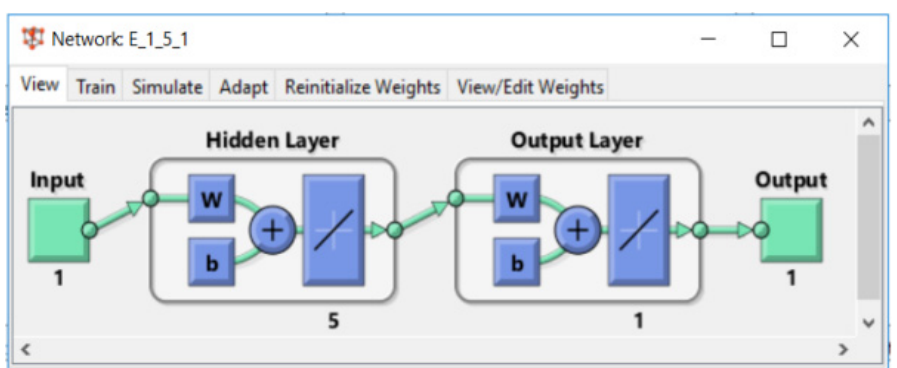

Fig. 21 Matlab, characteristics of ANNs with architectures 1-5-1. 


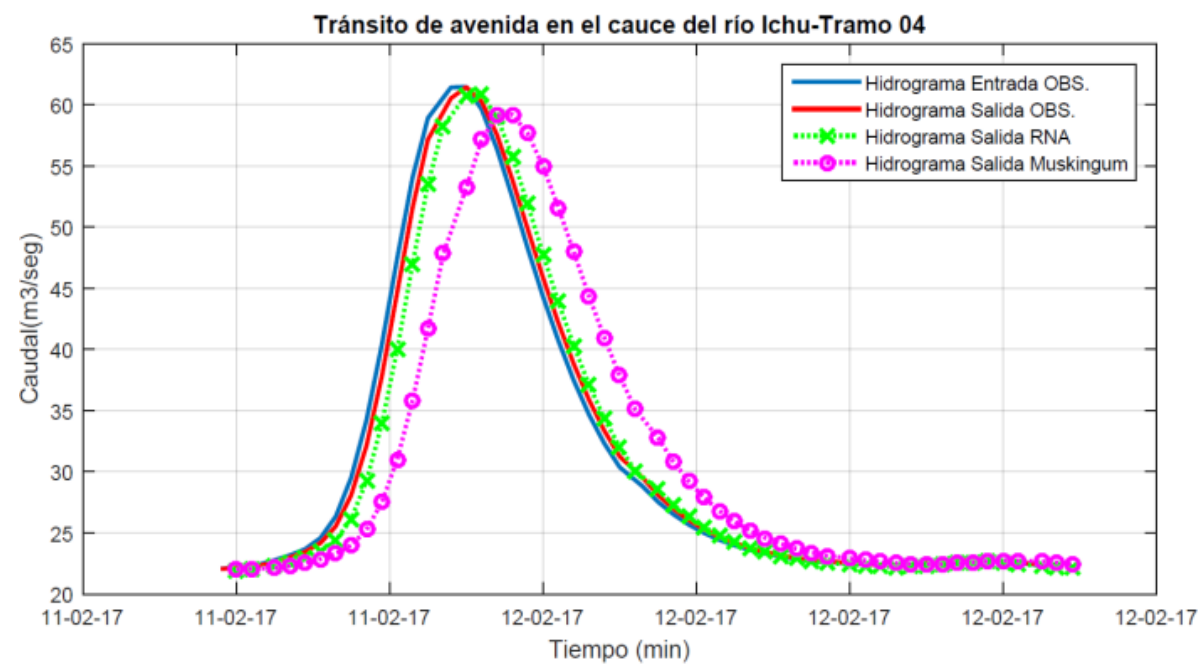

Fig. 22 Hydrograms of input and output observed, output hydrograph with ANNs and output hydrograph with Muskingum-Cunge, corresponding to section 4.

Case 02: For the second case of analysis, the hydrograph of the first case was taken, which was multiplied by factors 2,5 and 10 , to observe the behavior of the network at large magnitudes of hydrographs that may arise in the Ichu river. Table 5 shows the data for entering the network.

With the ANNs in double, quintuple and decuplicate cases, the income hydrographs have a similar

Table 5 Multiplicity hydrograph 2, 5 and 10.

\begin{tabular}{llllll}
\hline Date & Hour & I & I*2 & I*5 & $I^{*} 10$ \\
\hline 11-Feb.-17 & $14: 00$ & 22.07 & 44.14 & 110.34 & 220.68 \\
11-Feb.-17 & $14: 30$ & 22.19 & 44.37 & 110.94 & 221.87 \\
11-Feb.-17 & $15: 00$ & 22.42 & 44.85 & 112.12 & 224.24 \\
11-Feb.-17 & $15: 30$ & 22.77 & 45.54 & 113.85 & 227.70 \\
11-Feb.-17 & $16: 00$ & 23.17 & 46.35 & 115.87 & 231.73 \\
11-Feb.-17 & $16: 30$ & 23.68 & 47.35 & 118.39 & 236.77 \\
11-Feb.-17 & $17: 00$ & 24.59 & 49.18 & 122.95 & 245.89 \\
11-Feb.-17 & $17: 30$ & 26.36 & 52.73 & 131.82 & 263.63 \\
11-Feb.-17 & $18: 00$ & 29.53 & 59.06 & 147.65 & 295.30 \\
11-Feb.-17 & $18: 30$ & 34.26 & 68.51 & 171.28 & 342.55 \\
11-Feb.-17 & $19: 00$ & 40.41 & 80.82 & 202.06 & 404.11 \\
11-Feb.-17 & $19: 30$ & 47.48 & 94.96 & 237.40 & 474.79 \\
11-Feb.-17 & $20: 00$ & 54.07 & 108.15 & 270.37 & 540.73 \\
11-Feb.-17 & $20: 30$ & 58.92 & 117.84 & 294.61 & 589.22 \\
11-Feb.-17 & $21: 00$ & 61.42 & 122.85 & 307.12 & 614.23 \\
11-Feb.-17 & $21: 30$ & 61.47 & 122.94 & 307.34 & 614.68 \\
11-Feb.-17 & $22: 00$ & 59.63 & 119.26 & 298.16 & 596.32 \\
11-Feb.-17 & $22: 30$ & 56.39 & 112.78 & 281.94 & 563.88 \\
11-Feb.-17 & $23: 00$ & 52.44 & 104.88 & 262.20 & 524.39 \\
11-Feb.-17 & $23: 30$ & 48.28 & 96.57 & 241.42 & 482.83 \\
\hline
\end{tabular}

\begin{tabular}{llllll}
\hline 12-Feb.-17 & $00: 00$ & 44.32 & 88.65 & 221.62 & 443.23 \\
12-Feb.-17 & $00: 30$ & 40.72 & 81.44 & 203.61 & 407.21 \\
12-Feb.-17 & $01: 00$ & 37.48 & 74.96 & 187.41 & 374.82 \\
12-Feb.-17 & $01: 30$ & 34.67 & 69.33 & 173.34 & 346.67 \\
12-Feb.-17 & $02: 00$ & 32.31 & 64.62 & 161.56 & 323.11 \\
12-Feb.-17 & $02: 30$ & 30.37 & 60.74 & 151.85 & 303.69 \\
12-Feb.-17 & $03: 00$ & 28.80 & 57.60 & 144.00 & 288.00 \\
12-Feb.-17 & $03: 30$ & 27.53 & 55.07 & 137.67 & 275.34 \\
12-Feb.-17 & $04: 00$ & 26.52 & 53.04 & 132.60 & 265.19 \\
12-Feb.-17 & $04: 30$ & 25.68 & 51.36 & 128.39 & 256.78 \\
12-Feb.-17 & $05: 00$ & 24.99 & 49.98 & 124.95 & 249.90 \\
12-Feb.-17 & $05: 30$ & 24.43 & 48.85 & 122.13 & 244.26 \\
12-Feb.-17 & $06: 00$ & 23.97 & 47.94 & 119.86 & 239.71 \\
12-Feb.-17 & $06: 30$ & 23.60 & 47.21 & 118.02 & 236.03 \\
12-Feb.-17 & $07: 00$ & 23.31 & 46.61 & 116.53 & 233.05 \\
12-Feb.-17 & $07: 30$ & 23.06 & 46.12 & 115.31 & 230.62 \\
12-Feb.-17 & $08: 00$ & 22.86 & 45.73 & 114.32 & 228.63 \\
12-Feb.-17 & $08: 30$ & 22.71 & 45.41 & 113.53 & 227.05 \\
12-Feb.-17 & $09: 00$ & 22.58 & 45.17 & 112.92 & 225.83 \\
12-Feb.-17 & $09: 30$ & 22.49 & 44.98 & 112.46 & 224.91 \\
12-Feb.-17 & $10: 00$ & 22.43 & 44.86 & 112.15 & 224.29 \\
12-Feb.-17 & $10: 30$ & 22.40 & 44.79 & 111.98 & 223.96 \\
12-Feb.-17 & $11: 00$ & 22.40 & 44.81 & 112.02 & 224.04 \\
12-Feb.-17 & $11: 30$ & 22.45 & 44.90 & 112.26 & 224.51 \\
12-Feb.-17 & $12: 00$ & 22.56 & 45.11 & 112.78 & 225.55 \\
12-Feb.-17 & $12: 30$ & 22.69 & 45.38 & 113.45 & 226.90 \\
12-Feb.-17 & $13: 00$ & 22.79 & 45.57 & 113.93 & 227.85 \\
12-Feb.-17 & $13: 30$ & 22.80 & 45.60 & 114.00 & 228.00 \\
12-Feb.-17 & $14: 00$ & 22.73 & 45.47 & 113.67 & 227.33 \\
12-Feb.-17 & $14: 30$ & 22.61 & 45.23 & 113.07 & 226.13 \\
12-Feb.-17 & $15: 00$ & 22.47 & 44.94 & 112.36 & 224.72 \\
12-Feb.-17 & $15: 30$ & 22.36 & 44.72 & 111.79 & 223.58 \\
12-Feb.-17 & $16: 00$ & 22.37 & 44.74 & 111.85 & 223.70 \\
\hline & & & & &
\end{tabular}


expenditure with respect to the output hydrographs, it can be mentioned that the ANNs can simulate extraordinary flood events that occurred in the river. In Figs. 23-25 it can be seen that the ANNs resemble the output hydrograph.

Case 03: It corresponds to isolated flood, isolated flood was taken with different ranges of expenses covered in the validation stage of the network, the range is from $9.00 \mathrm{~m}^{3} / \mathrm{s}$ up to $83.00 \mathrm{~m}^{3} / \mathrm{s}$ approximately and that the forms of the floods taken in account are very different from each other, which allows affirming the possibility of covering floods included in these ranges.

In Figs. 26 and 27, the observed expenditures are shown in the Huancavelica hydrometric station, which corresponds to the section 05 of the channel and the hydrographs calculated with the trained neural network, it can be seen that there is a good correlation, which indicates that the ANNs have a good behavior to determine isolated floods in different ranges.

Case 04: For the development of the fourth case, the application of the ANNs to floods trains is analyzed. In Figs. 28 and 29, it is observed that the architecture 1-5-1, presents a good correlation with respect to the flows observed in consecutive floods events. Therefore, a good valuation can be given to the network, to simulate floods in the riverbed. In addition, after reviewing the historical information it can be seen that the floods trains are mainly due to consecutive rainstorms.

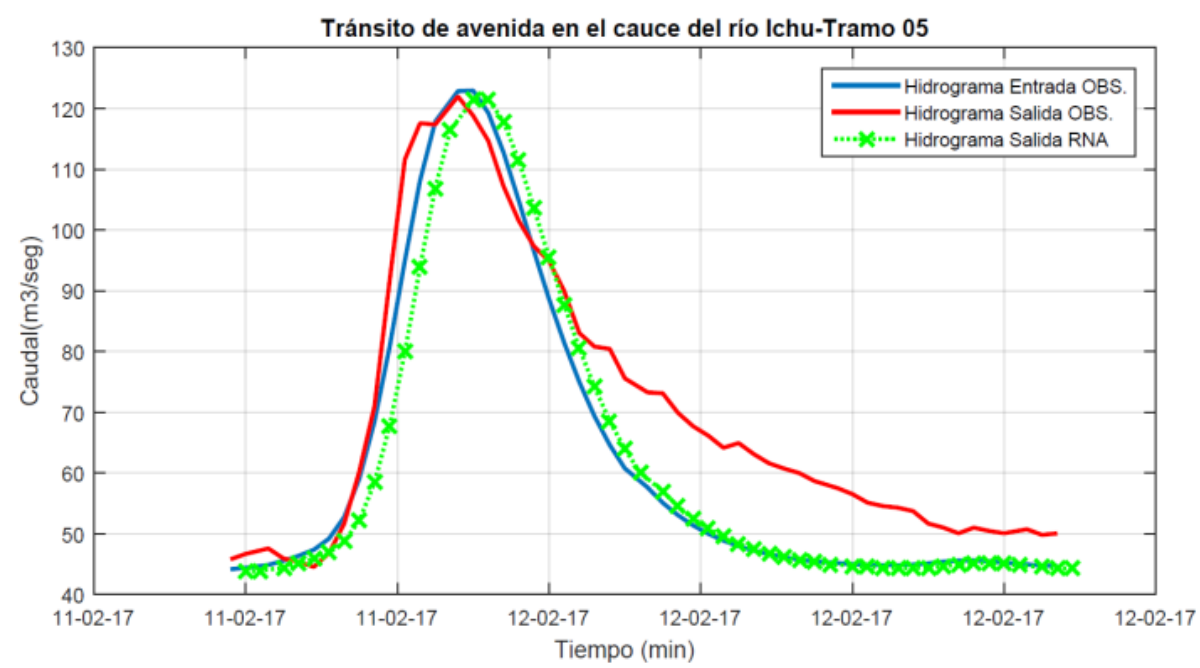

Fig. 23 Hydrograms of input and output observed and output hydrograph with ANNs, 11-12/Feb./2017 Section 05-Factor 2.

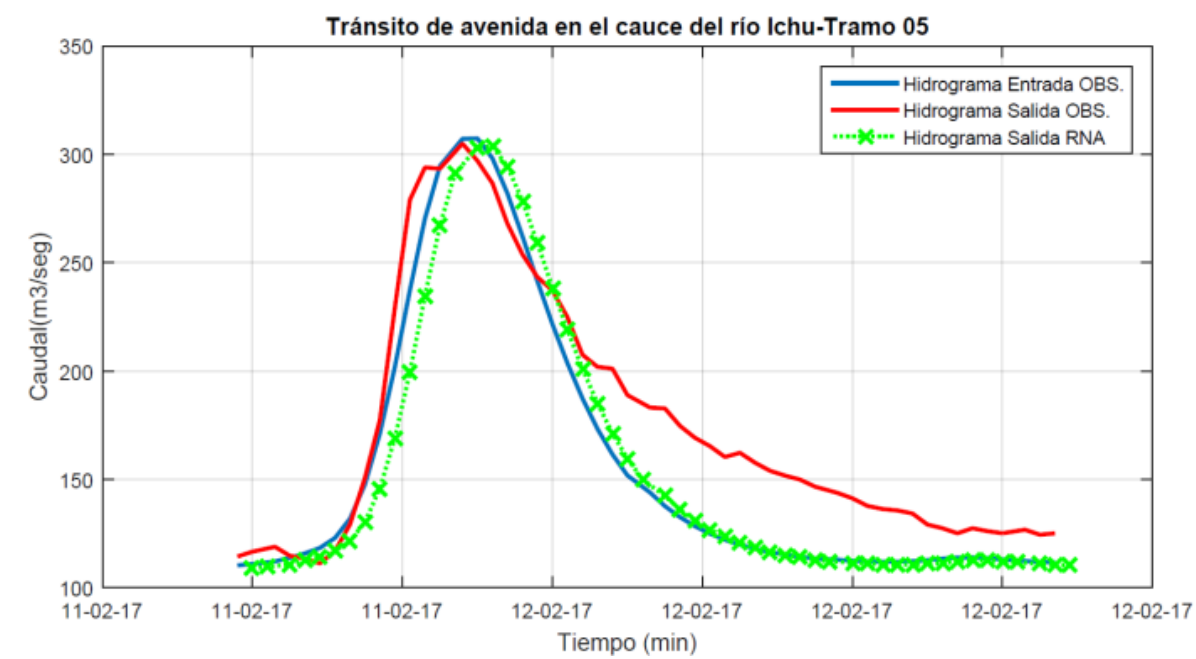

Fig. 24 Hydrograms of input and output observed and output hydrograph with ANNs, 11-12/Feb./2017 Section 05-Factor 5. 

Artificial Neural Networks

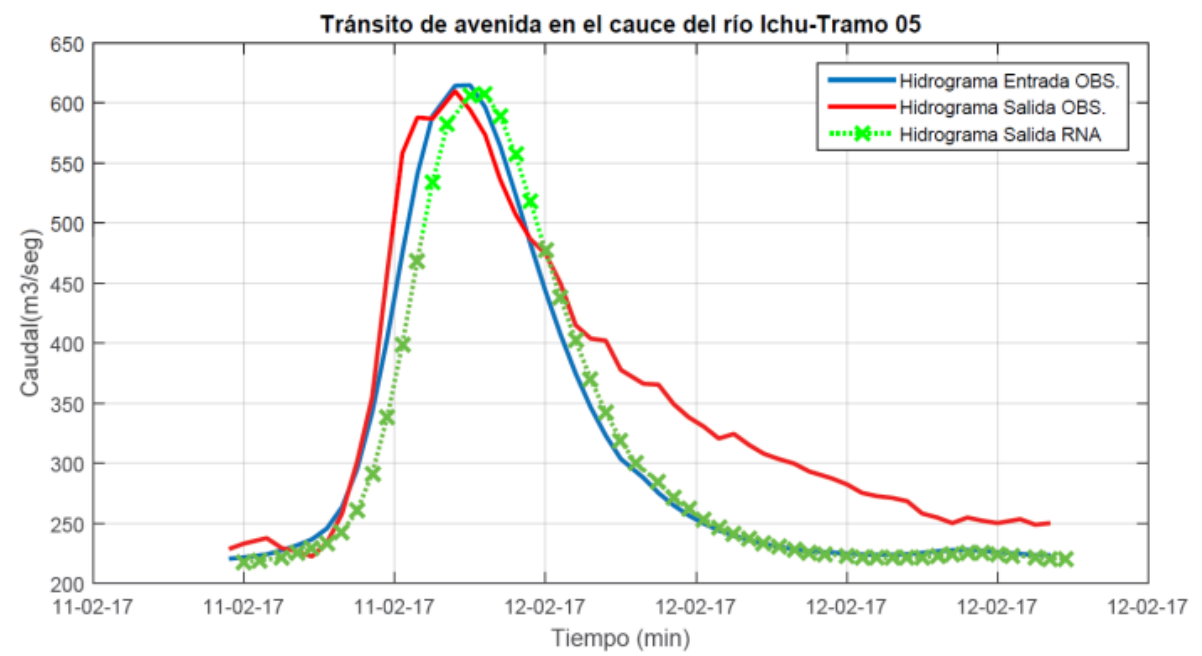

Fig. 25 Hydrograms of input and output observed and output hydrograph with ANNs, 11-12/Feb./2017 Section 05-Factor 10.

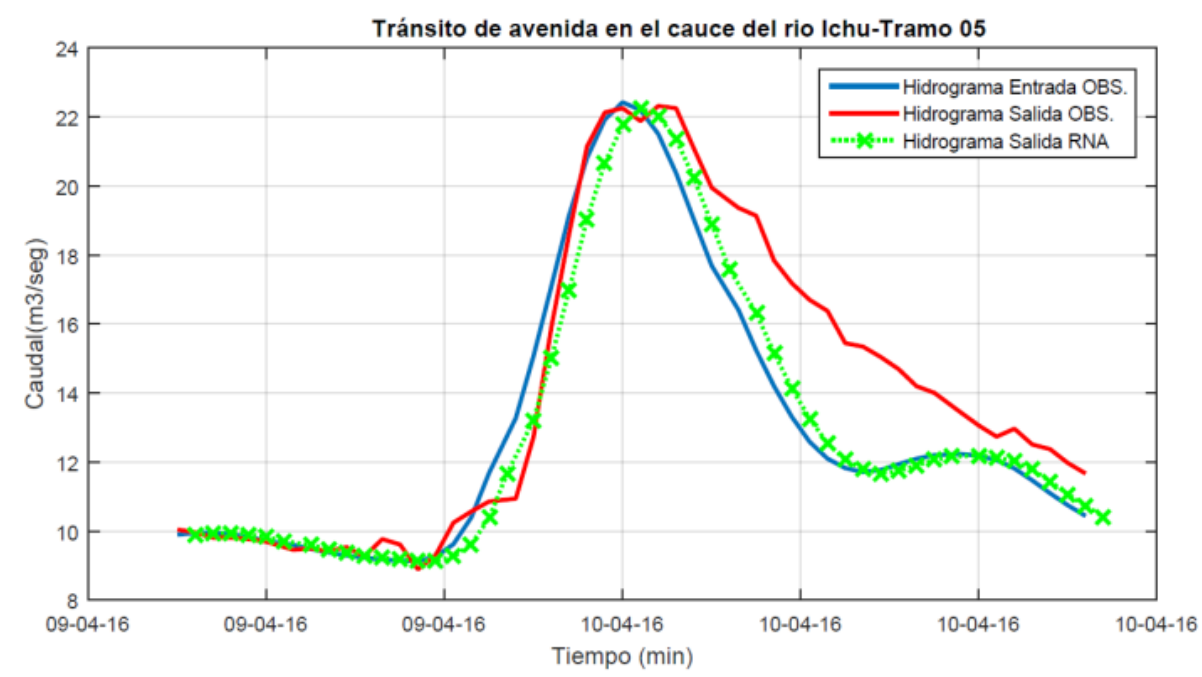

Fig. 26 Hydrograms of input and output observed and output hydrograph with ANNs, 09-10/Apr./2016 Section 05.

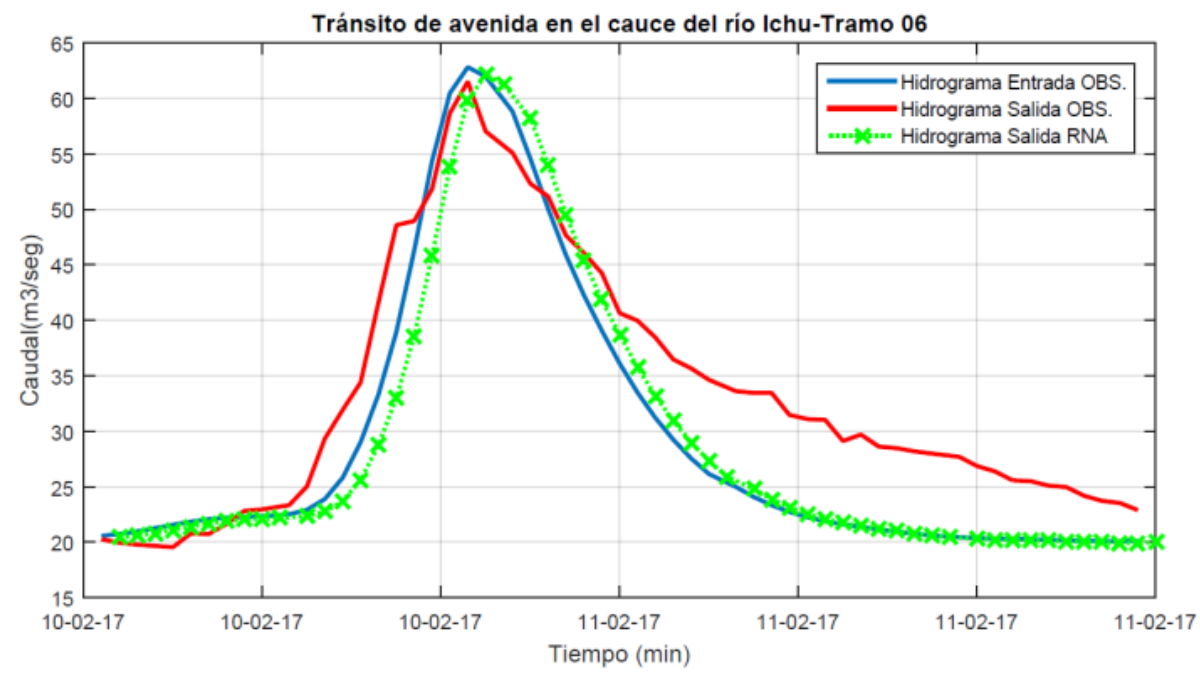

Fig. 27 Hydrograms of input and output observed and output hydrograph with ANNs, 10-11/Feb./2017 Section 05. 


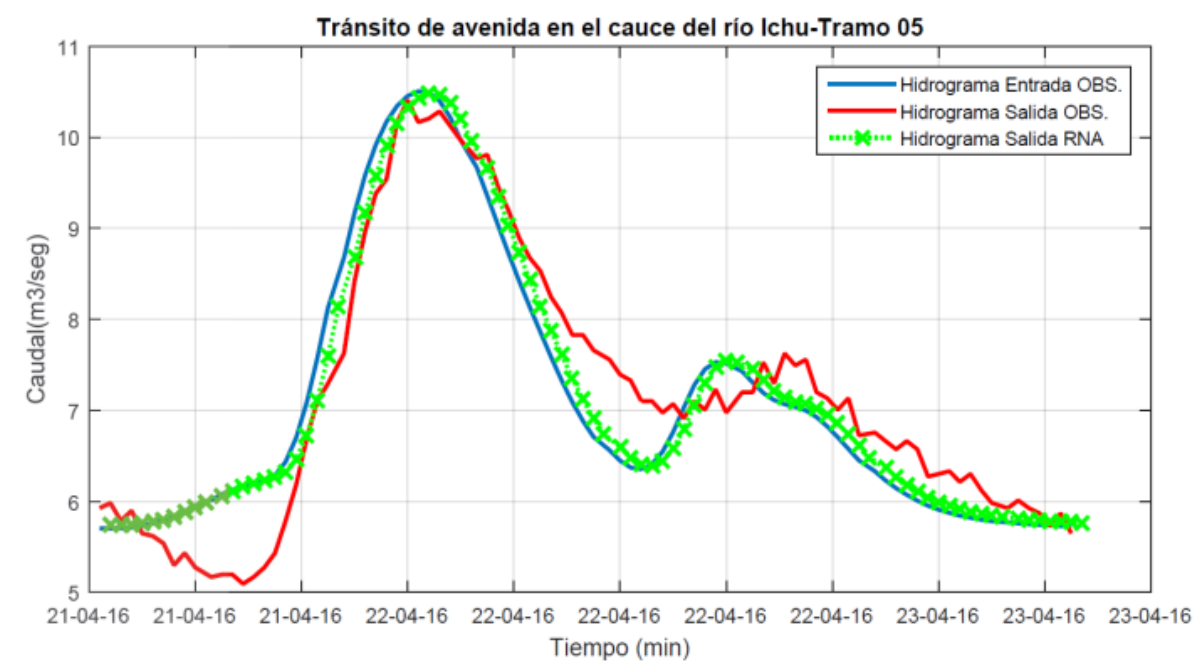

Fig. 28 Hydrograms of input and output observed and output hydrograph with ANNs, 21-23/Apr./2016 Section 05.

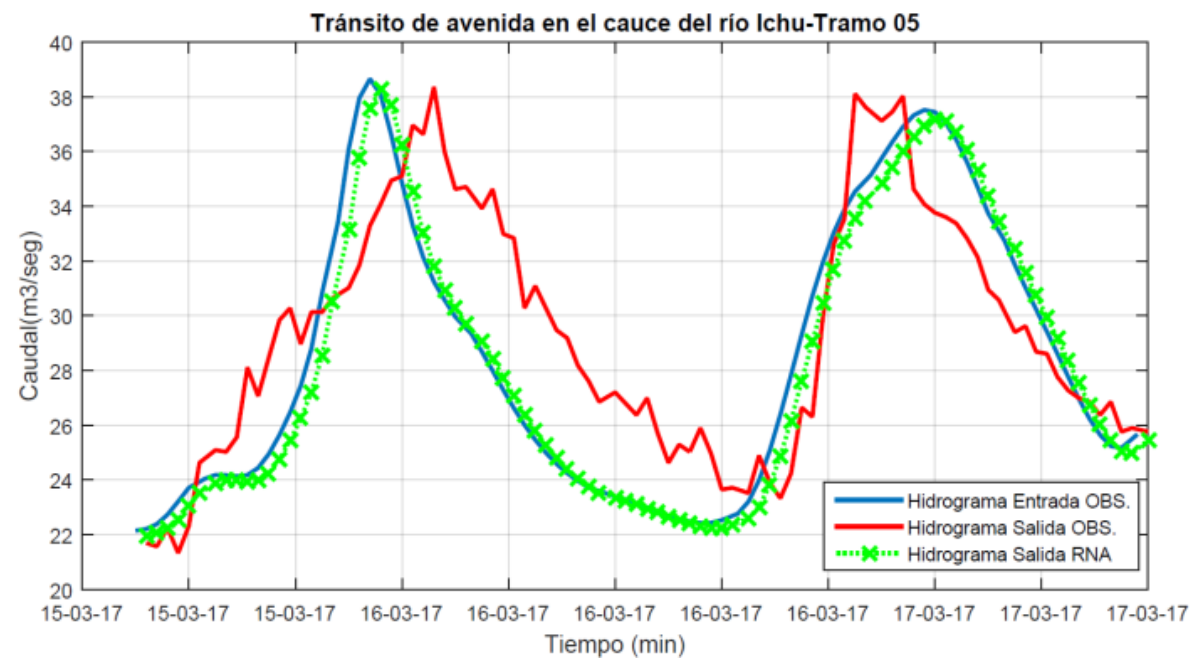

Fig. 29 Hydrograms of input and output observed and output hydrograph with ANNs, 15-17/Mar./2017 Section 05.

\subsubsection{Application of the Architecture of the ANN}

The statistic used to assess the research corresponds to the Nash-Sutcliffe model coefficient, to evaluate the similarity between the results of the hydrograph of the ANNs model and the observed hydrograph. The average of the coefficient $E$ is $0.991,0.956,0.970$, 0.959 and 0.420 for the sections $01,02,03,04$ and 05 respectively, determining an average value of 0.859 for the whole model.

\section{Conclusions}

The rain-runoff transformation process for the experimental basin of the Ichu river has been carried out, making use of the HEC-1 model and obtaining values of Nash-Sutcliffe $E$ efficiency coefficients equal to 0.851 and 0.828 for the calibration and validation stage respectively.

The technique of artificial intelligence has been used making use of architecture ANNs 1-5-1, providing the best adjustment to the phenomenon of flood rounting in the natural channel of the Ichu river. The Nash-Sutcliffe $E$ efficiency coefficient values of the model are 0.881 in the training stage and 0.859 in the validation.

\section{References}

[1] Maidment, D. R., ed. 1992. Handbook of Hydrology. New York: McGraw-Hill Inc..

[2] Anónimo. Tránsito de Avenidas en Cauces, Chapter 3, pp. $1-58$. 


\section{Artificial Neural Networks}

[3] Ponce, V. M., and Changanti, P. V. 1994. "Variable-Parameter Muskingum-Cunge Method Revisited." Journal of Hydrology 162 (3-4): 433-9.

[4] Tang, X. N., Knight, D. W., and Samuels, P. G. 1999. "Variable Parameter Muskingum-Cunge Method for Flood Routing in a Compound Channel." Journal of Hydraulic Research 37 (5): 591-614.

[5] Samimi, M., Kouchakzadeh, S., and Parvaresh-Rizi, A. 2009. "Verification of a Simplified Flood routing Method Based on Field Observation." In International Symposium on Water Management and Hydraulic Engineering Ohrid/Macedonia, pp. 909-20.

[6] Berezowsky, M., and Jiménez, A. 1995. Flujo no permanente en ríos. Instituto de Ingeniería de la UNAM, 574. (in Spanish)

[7] Ponce, V. M., and Lugo, A. 2001. "Modeling Looped Ratings in Muskingum-Cunge Routing." Journal of Hydrologic Engineering 6 (2): 119-24.

[8] Díez, R. P., Gomez, A. G., and de Abajo Martínez, N. 2001. Introducción a la inteligencia artificial: sistemas expertos, redes neuronales artificiales y computación evolutiva. Universidad de Oviedo. (in Spanish)

[9] Lopez, R. L., and Fernandez Fernandez, J. M. 2008. Las Redes Neuronales Artificiales fundamentos teóricos y aplicaciones practicas. Primera edición edition. (in
Spanish)

[10] Salas, R. 2004. Redes Neuronales Artificiales. Universidad de Valparaiso. Departamento de Computación.

[11] Graupe, D. 2007. Principles of Artificial Neural Networks. Advanced Series in Circuits and Systems, 2nd ed..

[12] Basogain, X. 2008. Redes neuronales artificiales y sus aplicaciones. Dpto. Ingeniería de Sistemas y Automática, Escuela Superior de Ingeniería Bilbao. (in Spanish)

[13] Cruz, P. P. 2010. Inteligencia Artificial con Aplicaciones a Ingeniería. México. (in Spanish)

[14] Parra, L. V. C. C. 2011. "Análisis de la robustez de un modelo de redes neuronales para la predicción de caudales en la cuenca alta del río paute." Master's thesis, Universidad Politécnica Salesiana. (in Spanish)

[15] Haykin, S. 1999. Neural Networks a Comprehensive Foundation, 2nd ed. Prentice Hall International, Inc..

[16] Matich, D. J. 2001. Redes neuronales: Conceptos básicos y aplicaciones. Cátedra de Informática Aplicada a la Ingeniería de Procesos-Orientaciçon I. (in Spanish)

[17] Kasabov, N. K. 1998. Foundations of Neural Networks, Fuzzy Systems, and Knowledge Engineering. Massachusetts Institute of Technology.

[18] Zurada, J. M. 1992. Intriduction to Artificial Neural Systems. West Publishing Company. 